\title{
A compreensão do residente médico em reumatologia no atendimento aos pacientes com fibromialgia
}

\author{
The understanding of rheumatology residents \\ concerning care for fibromyalgia patients
}

\author{
Ana Maria Canzonieri Maeda ${ }^{\mathrm{I}}$ \\ Daniel Feldman Pollak ${ }^{\mathrm{I}}$ \\ Maria Anita Viviani Martins ${ }^{\text {II }}$
}

\section{PALAVRAS-CHAVE \\ - Fibromialgia \\ - Pequisa Qualitativa \\ - Escolas médicas}

Recebido em: 18/10/2008 Reencaminhado em: 11/02/2009 Aprovado em: $13 / 03 / 200$

\section{KEY WORDS}

- Qualitative Research

- Schools, Medical
REVISTA BRASILEIRA DE EDUCAÇ̃̃O MÉDICA

\begin{abstract}
RES U M O
Este estudo busca a compreensão do residente médico em reumatologia no atendimento ao fibromiálgico. A síndrome é de difícil diagnóstico, e a dor é o fator mais importante. Objetivos: Entender como o residente compreende o atendimento; desvendar o que este atendimento gera. Métodos: Estudo qualitativo baseado na fenomenologia hermenêutica, com entrevista individual, gravada, sobre o tema da interrogação: "O que é isto para você: atender o fibromiálgico?". São feitas análises das significações dos residentes. O estudo foi realizado em três hospitais-escola públicos, com todos os residentes médicos do segundo ano. Resultados: $\mathrm{O}$ atendimento causa frustração, traz sentimento de impotência e gera indignação; o paciente sofre preconceito devido a idiossincrasias, a componentes sociais e à não adesão ao tratamento; o médico necessita de preparo emocional para atender - são requisitos necessários: saber ouvir e compreender a relação paciente-doença; o diagnóstico é marcado pela falta de comprovação laboratorial e subjetividade da anamnese; o médico necessita do apoio da psicologia, e o tratamento requer uma equipe multidisciplinar. Conclusão: $O$ atendimento é frustrante e gera sentimento de impotência, sendo preciso maior preparo psicológico na formação médica e uma atuação mais integrada entre medicina, psicologia e fisioterapia.
\end{abstract}

\section{A B S T R A C T}

This study focuses on the understanding of rheumatology residents in caring for fibromyalgia patients. The syndrome is difficult to diagnose, and pain is the most important symptom. Objectives: Understand how residents understand the care, and discover what this care leads to. Methods: Qualitative study based on hermeneutic phenomenology, with taped individual interviews answering the key question: "What does it mean to you to treat fibromyalgia patients?" The study analyzed the meanings provided by the residents. The research was performed in three public university hospitals, with second-year medical residents. Results: Care for fibromyalgia patients proved to be a source of frustration, bringing a feeling of powerlessness and indignation; patients suffer from prejudice due to idiosyncrasies, social components, and non-adherence to treatment; the physician needs to be emotionally prepared to provide care - requirements include knowing how to listen and understand the patient-illness relationship; the diagnosis is marked by lack of laboratory confirmation and subjectivity in the work-up; the physician needs support from psychology, and the treatment requires a multidisciplinary team. Conclusion: Care is frustrating and generates a feeling of powerlessness. It requires greater psychological preparation during medical training and a more integrated approach between medicine, psychology, and physical therapy.

\footnotetext{
I Universidade Federal de São Paulo, São Paulo, São Paulo, Brasil.

${ }^{I I}$ Pontifícia Universidade Católica de São Paulo, São Paulo, São Paulo, Brasil. 


\section{INTRODUÇÃO}

A fibromialgia é uma síndrome cujo fator mais importante é a dor, coexistindo com alterações de fundo emocional e até distúrbio psíquico, o que dificulta o tratamento médico. O indivíduo apresenta múltiplos pontos dolorosos sensíveis ao toque, chamados tender points, com a presença de fadiga, distúrbios do sono e do humor e cefaleia, conceitos estes trazidos pelo Vancouver Fibromyalgia Consensus Group, em 1994 (Wolfe, 1996 apud Falcão ${ }^{1}$.

A fibromialgia tem uma frequência aproximada de $15 \%$ nas clinicas de reumatologia e em torno de 5,7\% nos demais consultórios. A predominância é feminina ( $75 \%$ a $90 \%$ ), com um pico de incidência entre 20 e 60 anos de idade (Wolfe, 1989 apud Falcão ${ }^{1}$ ). O diagnóstico se baseia em dados clínicos, pois normalmente não há alterações em exames laboratoriais ou de imagem. E a frequência de casos vem aumentando a cada ano.

Segundo Yoshikawa ${ }^{2}$, o quadro doloroso modifica o estilo e a qualidade de vida dos pacientes, restringindo atividades, trabalho e as relações familiares e sociais.

A demanda de atendimento a pacientes fibromiálgicos vem aumentando. Sabe-se que há dificuldade em diagnosticar e tratar esse tipo de paciente em função da sintomatologia e do tipo de queixa relatada, que parece exacerbada e envolta em conteúdos extrapaciente. O fibromiálgico transita por diversas especialidades médicas, e em alguns casos o diagnóstico é feito tardiamente devido à falta de compreensão em relação ao paciente.

Decidiu-se realizar uma pesquisa que demonstre como o residente médico em reumatologia compreende o atendimento ao paciente com fibromialgia, para verificar as dificuldades no diagnóstico e tratamento do paciente segundo a visão do médico, pois não há na literatura dados sobre este assunto.

A importância deste estudo reside na compreensão do paciente e na adequação da relação médico-paciente, que, nestes casos, necessitam de um olhar além do sintoma físico, devido à sintomatologia psíquica presente.

Considerou-se mais adequado o uso da metodologia qualitativa devido à intencionalidade da amostra. Chegou-se à seguinte interrogação como a mais apropriada para estimular o residente a expressar espontaneamente o que significa para ele esse tipo de atendimento: "O que é isto para você: atender ao fibromiálgico?".

Admite-se que com esta interrogação o residente fará uma pausa em seu pensamento e se remeterá à significação interna do que é para ele atender esse tipo de paciente, e sua resposta expressaria sua percepção do ato de atender.

\section{OBJETIVOS}

\section{Objetivo geral}

Entender como o residente médico em reumatologia compreende o atendimento ao paciente com fibromialgia.

\section{Objetivo específico}

Desvendar o que o atendimento ao fibromiálgico gera no residente.

\section{REVISÃO DA LITERATURA}

\section{Compreendendo o adoecer}

A "dor" é considerada um fenômeno multifatorial, cuja sensação e percepção variam individualmente e de acordo com a influência de fatores biológicos, psicológicos e sociais. Pode-se considerá-la como resultante do desequilíbrio entre a quantidade e a qualidade da estimulação nociceptiva e a ativação do sistema supressor de dor.

Segundo a teoria da neuromatriz de Melzack, a dor é o resultado de descargas de uma rede neuronal cerebral que envolve componentes somatossensoriais, límbicos e tálamo-corticais e não somente um produto direto de estímulos sensoriais nociceptivos desencadeados por uma lesão tissular ou processo inflamatório.

A fibromialgia é caracterizada por alterações no processo de estímulos e respostas no sistema nervoso central (SNC), que podem ter causas ligadas aos fatores: (a) psicológicos: personalidade, humor e atitude; (b) sociológicos: trabalho, status, cultura e relações familiares; (c) biológicos: neuropeptídeos.

Bernardo ${ }^{3}$ aponta a falta de preparo dos profissionais da área da saúde para o manejo da "dor". Cita que, segundo Jeans (1983), de 1970 a 1975 foram publicados 1.330 trabalhos sobre "dor" e não se enfatizou o tema na formação dos profissionais.

Ao atender um paciente com dor, é visível a expressão de emoções que podem estar relacionadas à "dor" e à incapacidade que esta produz. Por isso, além do desafio da investigação diagnóstica e do tratamento, a análise socioemocional deve estar presente no atendimento, a fim de se enxergar o paciente como "biopsicossocial".

Na fibromialgia, o estado emocional alterado do paciente é um fator importante, pois marca sua dificuldade em lidar com "problemas", anterior à doença ou somando-se ao aparecimento desta, formando, assim, um circuito: o estado emocional interfere na "dor", e esta interfere no estado emocional. 
Para Feldman ${ }^{4}$, cada gesto, cada palavra tem uma ação sobre o paciente, e cabe ao profissional usá-la adequadamente. Inclusive, o profissional da área da saúde deveria ser mais bem preparado para lidar com pessoas, em vez de ser preparado para lidar com pessoas, em vez de ser preparado para lidar com a doença.

Barros $^{5}$ cita Rego (2003), Muñoz e Muñoz (2003) e Froncon et al. (1998) para falar da insatisfação com o preparo dos médicos em relação ao "homem". A ciência, sob a visão positivista, contaminou a prática médica com um pensamento racional e reducionista, garantindo a objetividade e a neutralidade da atitude médica em relação ao paciente.

Para o profissional, o exercício da medicina envolve lidar com o próprio sofrimento além do alheio, pois na relação médico-paciente estão presentes emoções de ambas as partes. E o acolhimento por parte do médico só será possível quando ele estiver atento às suas atitudes no exercício do papel profissional, pois o paciente, acima de qualquer diagnóstico, solicitação de exame e prescrição de medicação, espera de seu médico o acolhimento à sua pessoa.

\section{Formação médica}

Em Gadamer6 , a palavra "formação" designa a maneira pela qual o homem aperfeiçoa suas aptidões, processo em contínua evolução que permite ao homem se apropriar daquilo que lhe é ensinado.

Segundo Ismael ${ }^{7}$, uma pesquisa feita com 30 pessoas, entre 30 e 65 anos, sobre o que esperavam receber do atendimento médico apontou quatro atitudes: confortar, escutar, olhar e tocar. Elas atribuíram a essas atitudes a missão do médico, o que, em síntese, representa o humanismo no atendimento médico pregado por Asclépio e Hipócrates.

Para Nogueira-Martins ${ }^{8}$, o modelo médico é aquele que entende que curar envolve uma atitude humano-científica, que compreende o biológico, o psicológico e o cultural.

Estabelecer um relacionamento médico-paciente exige uma compreensão do comportamento humano e um olhar voltado para o outro. Por isso, a fim de diagnosticar, lidar e tratar o paciente, o profissional de saúde deve aprender a ouvir. Segundo Batista ${ }^{9}$, discute-se que a formação médica implica três pontos fundamentais: competência, habilidades e atitudes (CHA).

O aprendizado e o desenvolvimento do papel profissional são produto da interação entre o indivíduo e o meio educacional. A formação médica ocorre por meio da vivência do indivíduo ao longo do curso e fora dele, com experiências adquiridas na prática junto ao paciente e com os modelos de profissionais com os quais se interagiu.
Lacaz (1997), apud Millan ${ }^{10}$, diz que o médico deve compreender a linguagem da dor, da angústia, do medo e do sofrimento, para que possa falar à alma de seus pacientes.

O predomínio do conceito organicista no processo saúde-doença leva o médico a utilizar ferramentas organicistas para atuar na resolução de problemas. Falta construir na graduação em saúde um aprendizado que propicie mais ao aluno a prática integrada dos recursos organicistas e humanísticos ${ }^{11}$.

Nas Diretrizes Curriculares Nacionais (DCN) de 2001, consta que a graduação em Medicina deve proporcionar uma formação generalista, humanista, crítica e reflexiva, que caminhe por dimensões éticas e humanísticas, a fim de desenvolver no aluno atitudes e valores voltados para a cidadania.

A partir de Flexner (1910), a educação médica passou a ser entendida como um processo de iniciação científica que segue um modelo hierárquico e autoritário que dá ênfase ao conteúdo e ao resultado quantificado. É uma escola que divide o conhecimento em especialidades e subespecialidades, centrada no professor e na transmissão do conteúdo, e que, embora aconselhe a prática do humanismo, tem uma estrutura de trabalho individualista, biologicista, hospitalocêntrica e com ênfase nas especializações $^{12}$.

O processo de capacitação do profissional em saúde requer a articulação entre a prática clínica e a pesquisa laboratorial, sem perder de vista o "Homem", em seu conceito mais amplo, como um ser biopsicossocial.

Em virtude da departamentalização, fica a critério da disciplina Psicologia Médica trabalhar com os graduandos em Medicina a visão de "Homem". Balint foi o precursor desta disciplina devido aos trabalhos realizados com grupos de médicos, com a finalidade de auxiliá-los a tratar o paciente como pessoa.

A residência médica é um sistema de ensino de pós-graduação destinado a médicos, é um curso de especialização de treinamento em serviço ${ }^{13}$. Segundo Nogueira-Martins (1998), apud Macedo $^{14}$, é com o treinamento que o residente molda a identidade profissional, pois desenvolve a aquisição do conhecimento e das habilidades, além do amadurecimento afetivo.

O adequado seria investir mais em treinamento de profissionais da área da saúde, possibilitando-lhes o uso de técnicas que facilitem o contato com o paciente e levando-os a perceber e a compreender melhor os conteúdos emocionais subjacentes à fala do paciente. Deste modo, a formação do profissional em saúde e, principalmente, do médico estaria voltada para a capacidade de escuta. 


\section{Fenomenologia hermenêutica em pesquisa qualitativa na área da saúde}

Segundo a literatura, as pesquisas, normalmente, não abrangem o vivenciar de experiências do ato de atender do médico. As inferências são sobre trabalho, doença ou o estresse que o ato de exercer a medicina causa aos profissionais. Por isso, o foco deste estudo é a compreensão do médico no atendimento ao paciente com fibromialgia.

Desenvolve-se, portanto, uma pesquisa qualitativa, para compreender o significado do discurso do residente médico sobre o atendimento ao paciente com fibromialgia. Minayo ${ }^{15}$ sustenta que a metodologia qualitativa não deve ser vista como uma alternativa ideológica às metodologias quantitativas, mas como capaz de incorporar a questão do significado e da intencionalidade, sendo a fenomenologia o método qualitativo que tem tido maior relevância na área da saúde.

O termo fenomenologia foi criado pelo matemático e filósofo Lambert (1728-1777) e difundido por Hamilton (1788-1856), como sendo a descrição imediata dos fatos e ocorrências psíquicos anteriores a qualquer explicação teórica ${ }^{16}$.

Para Laurenti ${ }^{17}$, a fenomenologia teve sua origem com Hurssel (1858-1939). Seus principais seguidores foram Heidegger (1889-1976), Merleau-Ponty (1908-1961) e Sartre (1905-1980). Hurssel estava interessado em estudar a intencionalidade, que é o ato de dar um significado; é entender as coisas a partir das vivências dos indivíduos e como estes estabeleciam os significados para suas vivências. $O$ fenômeno integra a consciência do indivíduo e a realidade exterior, pois não há uma pura consciência, separada de qualquer objeto.

Merleau-Ponty (1999), apud Rossi ${ }^{16}$, traz que a fenomenologia trata de descrever e não de explicar o fato. Resta à hermenêutica o processo de explicação. Segundo Feijoo ${ }^{18}$, a hermenêutica representa todo o esforço de interpretação científica de um texto difícil que exige uma explicação. Gadamer (1987), apud Minayo $^{15}$, afirma que a hermenêutica é a busca de compreensão que dá sentido à comunicação entre seres humanos.

O apoio de Hurssel e Merleau-Ponty é trazido a esta pesquisa para explicar o conceito de fenomenologia e a adequação de seu uso para discutir os discursos dos residentes e em que consistia o fenômeno do atendimento ao paciente fibromiálgico.

Heidegger cita que, ao se questionar, busca-se o sentido, e quando se investiga propõe-se a questão previamente concebida ${ }^{18}$.

Para Gadamer ${ }^{19}$, o sentido da pergunta é a única direção que a resposta pode adotar, e o como se pergunta interfere na resposta. Perguntar é mais difícil que responder.
Toda a intenção do que se deseja saber é colocada na pergunta, esperando-se que esta cause uma ruptura no pensamento do interrogado; este é colocado sob determinada perspectiva de aquilo que se interroga permanecer em suspenso até a exposição da resposta.

Na fala, o homem expressa seus diferentes estados de ânimo, sua visão do mundo. Mostrar-se a si mesmo é discursar, é expressar-se no sentido da entidade da palavra, do gesto, do silêncio, enfim, do comportamento. Daí, aquele que investiga pode se guiar pelo diálogo ${ }^{18}$.

Estudos de Gadamer orientaram a formulação adequada da interrogação feita ao sujeito de pesquisa, para que este pudesse responder exatamente aquilo que lhe foi perguntado, e o sentido do uso da hermenêutica como auxiliar na interpretação de significados subjacentes nas respostas dos sujeitos que representam os discursos dos residentes médicos.

Turato $^{20}$ aborda a importância da atuação do pesquisador na metodologia qualitativa, pois seu estado mental, sua atitude frente ao entrevistado, seu grau de conhecimento sobre o assunto, sua experiência de vida como pessoa e profissional influenciarão o setting (o contexto do ambiente delimitado para o encontro).

Em função das poucas pesquisas qualitativas na área da saúde, é necessária uma mudança de paradigma. Sem desprezar o rigor científico das medições, mas entendendo que também se pode usar o conhecimento não quantificado para tornar relevante o que é observado e não mensurável.

A pesquisa qualitativa permite a construção do conhecimento a partir de respostas que expressam significados profundos, não quantificáveis e oriundos de observação.

\section{MÉTODO}

\section{Tipo de estudo}

Trata-se de uma pesquisa qualitativa, realizada em três hospitais-escola da rede pública. Foram convidados a participar do estudo todos os residentes do segundo ano de reumatologia: hospital A - 6; hospital B - 2; hospital C - 7. Os locais e a doença foram escolhidos intencionalmente.

Este é um estudo da compreensão do atendimento e não da relação médico-paciente, no qual se busca compreender o tipo de acolhimento à "dor" que é feito pelo residente e o que ele sente ao fazer isto.

A pesquisa foi realizada por meio de discursos espontâneos orais, em que o residente discorre livremente sobre o tema da interrogação: “O que é isto para você: atender ao fibromiálgico?". 


\section{Validade}

A pesquisa qualitativa trata exclusivamente de significados e processos, e não de medidas. Os resultados são apresentados de forma descritiva, e não numérica. É de extrema importância ressaltar que este tipo de pesquisa depende do rigor da intuição e da habilidade do pesquisador em manusear técnicas e recursos para retratar o fenômeno, pois não há hipóteses formuladas, nem existem critérios absolutos na coleta dos dados.

Não se utilizou o critério de saturação porque a intenção foi coletar a resposta de todos os residentes, num total de 15 médicos, nos três hospitais.

A autoridade do pesquisador também se manifesta pela circunstância de que aquilo que ele pesquisa e investiga faz parte de seu mundo, o que certamente abarca o conhecimento operativo e o científico.

O pesquisador possui formação em psicologia clínica e atua há quatro anos com pacientes fibromiálgicos, o que diminui ruídos na comunicação e facilita a compreensão do que foi dito pelo residente.

A interrogação foi feita ao residente sempre do mesmo modo, deixando-o livre para falar. Em todas as entrevistas, entrevistados e entrevistador mantiveram o tom de voz calmo e a expressão verbal e corporal tranquila. Não houve nenhuma intercorrência.

\section{Sujeitos}

Todos os residentes tinham sido avisados antecipadamente pelos chefes da disciplina e, portanto, ninguém se mostrou surpreso ou indisponível quando abordado pelo entrevistador.

Agendou-se com o residente o dia e o horário. O encontro ocorreu no ambulatório. Inicialmente, houve uma explicação verbal sobre a pesquisa e entregou-se a carta-convite com os mesmos dados, para que o residente lesse e assinasse. Todos os residentes aceitaram o convite sem constrangimento.

A entrevista foi gravada a sós. O gravador era mostrado após as explicações sobre a pesquisa e a coleta da assinatura de consentimento. Foram levados a campo dois gravadores, um digital e um com fita, tendo sido usado apenas o digital. A menor entrevista durou cinco minutos, e a mais longa, 21 minutos. Não houve predominância de tempo em relação ao hospital.

O período decorrido entre a primeira entrevista e a última foi de 45 dias (dezembro/2004 a janeiro/2005). No hospital A, foram feitas duas visitas; no hospital B, três visitas; no hospital C, uma visita.

O primeiro período de análise das transcrições durou três meses (fevereiro a abril/2005). O segundo período, também com a duração de três meses (maio a julho/2005), se refere à separação das unidades significativas em ponto comum entre os sujeitos entrevistados. O terceiro período de análise durou dez meses (agosto/2005 a julho/2006). Todas estas etapas contaram com o auxílio de orientador especializado na área da fenomenologia hermenêutica. Paralelamente, desenvolvia-se o estudo teórico sobre a fenomenologia para embasar as interpretações da fala do sujeito.

\section{Entrevista gravada}

Aqualidade da entrevista se divide em conclusão da entrevista e registro e armazenamento da informação. Todos os registros das entrevistas são lançados diretamente no computador, pelo sistema digital do gravador, no mesmo dia da coleta, em forma de texto corrido. Só após o término de todas as entrevistas é que se inicia a fase de análise.

O discurso do sujeito sofre três reduções para se alcançar o princípio de sentido atribuído. Busca-se o que é a "lei" (comum) nos discursos dos sujeitos.

Discurso integral

Escolheu-se aleatoriamente um exemplo de discurso para que se possa acompanhar o método de análise: Hospital A Discurso 3.

ENTREVISTADOR: Gostaria que você respondesse da forma mais ampla possível. O que é isto para você: atender ao fibromiálgico?

ENTREVISTADO: Bom, é um paciente complexo, você tem que ver vários parâmetros, não só reumatológico, principalmente psicológico. Eles são passivos, têm uma relação passiva com a doença. Muitos deles, na grande maioria, acho que fundamental para o tratamento é mudar essa visão da doença. Parece que o médico tem obrigação de melhorar. E dá a impressão de que eles não sabem, não têm o que fazer, não querem fazer nada para melhorar. Essa é a grande impressão que eu tenho. Quando eles percebem que eles estão fazendo exercício físico, tomando a medicação, fazendo as atividades que a gente manda, eles se motivam a fazer mais isto. Se motivam a tratar a doença, aumentar a carga de exercício, fazer o tratamento. $\mathrm{O}$ aspecto psicológico é fundamental.

\section{Análise idiossincrática}

O primeiro procedimento foi ler o texto e grifar frases que respondem a pergunta: "O que é isto para você: atender ao fibromiálgico?". Em seguida, separar as frases que recebem o nome de discurso na linguagem do sujeito, que são analisadas, sintetizadas e reescritas numa linguagem formal (norma culta), recebendo o nome de unidades significativas.

As unidades significativas sofrem uma nova análise, são sintetizadas e reescritas de forma a expressar a essência do pensa- 
mento do sujeito, o sentido por ele atribuído, e recebem o nome de asserções articuladas. São 15 discursos analisados e sintetizados em 37 asserções articuladas.

Análise nomotética

As asserções articuladas são separadas e agrupadas de acor- e a não adesão ao tratamento exigem um exaustivo exercício de perseverança do médico.

3. O médico necessita de preparo emocional para atender o fibromiálgico. São requisitos necessários: saber ouvir, ter paciência, solidariedade, compaixão e compreensão da rela-

Quadro 1

Análise idiossincrática: Discurso 3 - Hospital A

\begin{tabular}{|l|l|l|}
\hline Discurso na linguagem do sujeito & Unidades significativas & Asserções articuladas \\
\hline $\begin{array}{l}\text { 1. É um paciente complexo, você tem que ver } \\
\text { vários parâmetros, não só o reumatológico, } \\
\text { principalmente o psicológico. }\end{array}$ & $\begin{array}{l}\text { 1. O paciente fibromiálgico é complexo } \\
\text { em virtude de parâmetros } \\
\text { reumatológicos e psicológicos. (1) }\end{array}$ & $\begin{array}{l}\text { 1. O paciente fibromiálgico é } \\
\text { complexo em virtude de parâmetros } \\
\text { reumatológicos e psicológicos. (1) }\end{array}$ \\
\hline $\begin{array}{l}\text { 2. Eles são passivos, têm uma relação passiva } \\
\text { com a doença. }\end{array}$ & $\begin{array}{l}\text { 2. Atender pacientes fibromiálgicos } \\
\text { tem relação com a passividade do } \\
\text { paciente e ainda colocam sobre o } \\
\text { médico a expectativa da melhora } \\
\text { obrigatória. }(2,3)\end{array}$ & $\begin{array}{l}\text { 2. O médico residente necessita } \\
\text { preparo para avaliar e intervir na } \\
\text { ambiguidade da condição do } \\
\text { paciente. (2,3) }\end{array}$ \\
\hline $\begin{array}{l}\text { 3. Parece que o médico tem obrigação de } \\
\text { melhorar. }\end{array}$ & $\begin{array}{l}\text { 3. O paciente fibromiálgico melhora } \\
\text { quando percebe como eficaz a } \\
\text { orientação médica. (4) }\end{array}$ & \\
\hline $\begin{array}{l}\text { 4. Quando eles percebem que fazendo } \\
\text { exercício físico, tomando a medicação, } \\
\text { fazendo atividades que a gente manda, eles } \\
\text { melhoram, eles se motivam. }\end{array}$ & & \\
\hline
\end{tabular}

do com o significado. Unem-se as asserções por semelhança de conteúdo, anota-se o número do discurso geral e a qual asserção se refere, nesse discurso. O resultado é a proposição final que expressa todo o sentido atribuído por todos os residentes ao atenderem o fibromiálgico.

\section{Análise de proposição}

O resultado da análise nomotética dá origem a cinco proposições finais que resumem o significado de todas as respostas dadas por todos os residentes:

1. O atendimento ao fibromiálgico dependerá dos efeitos desse paciente sobre o estado de espírito do médico. Esse atendimento entedia, causa frustração, traz sentimento de impotência e gera, inclusive, indignação. Produz cansaço, exaurindo o médico pela exigência do paciente, que tem a expectativa de cura.

2. O paciente fibromiálgico sofre preconceito e resistência médica em virtude de múltiplas pressões exercidas sobre o profissional, tais como: idiossincrasias do paciente e a descoberta daquilo que mais o incomoda. Componentes sociais ção paciente-doença, pois o paciente, além do adoecimento físico, tem uma carência emocional. Atender e tratar o fibromiálgico dependem mais do paciente do que da ação médica, devido a um não comprometimento grave do organismo, o que inspira maior tranquilidade no atendimento.

4. O diagnóstico é marcado pela falta de comprovação laboratorial, pela subjetividade da anamnese, por múltiplos fatores que dificultam o atendimento médico e pela compreensão do tratamento por parte do paciente. Todos estes fatores podem levar a uma inadequação de diagnóstico.

5. O médico necessita do apoio da psicologia para auxiliá-lo na orientação, na explicação e na mudança de atitude do paciente em relação à doença, pois o resultado do tratamento tem eficiência na mudança de hábito e não na utilização da medicação. É um tratamento que requer uma equipe multidisciplinar devido à complexidade de fatores presentes no adoecimento. Sabe-se da necessidade de exercício físico e acompanhamento psicológico, aliados à medicação para obtenção de resultado positivo. 


\begin{tabular}{|c|c|c|c|c|}
\hline \multicolumn{5}{|c|}{$\begin{array}{c}\text { Quadro } 2 \\
\text { Proposição } 1\end{array}$} \\
\hline Asserção articulada & Discurso & Asserção & & Proposição \\
\hline 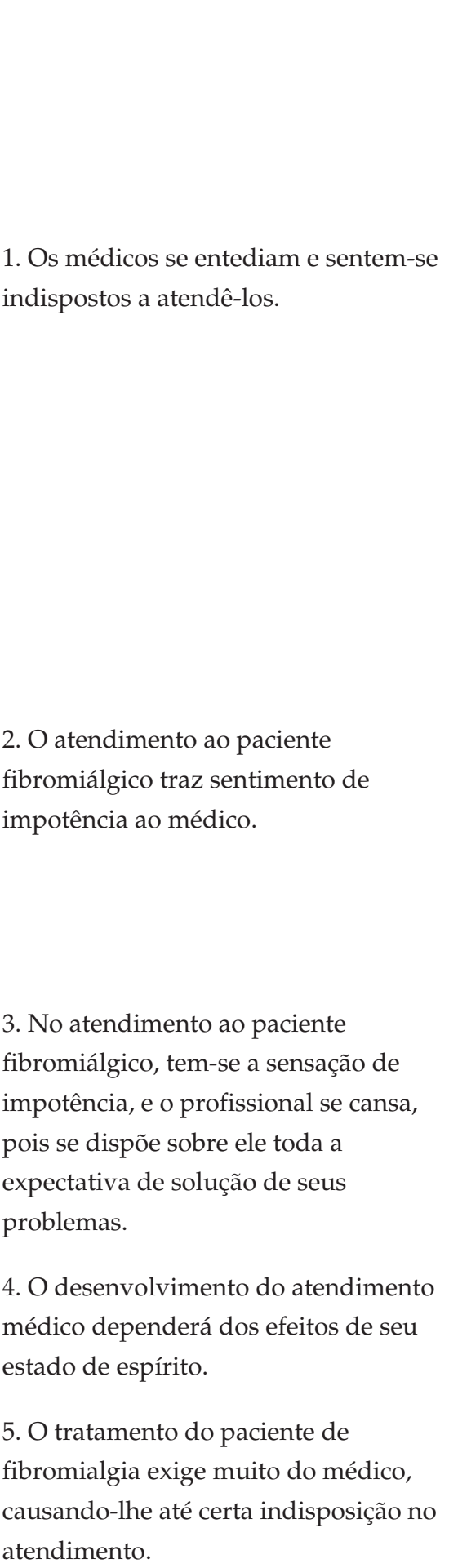 & \begin{tabular}{|l}
5 \\
\\
\\
\end{tabular} & 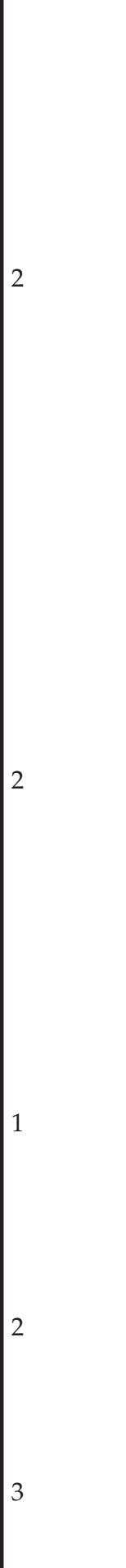 & $\begin{array}{l}\text { 1. O atendimento ao } \\
\text { fibromiálgico dependerá } \\
\text { dos efeitos desse paciente } \\
\text { sobre o estado de espírito } \\
\text { do médico. (5) } \\
\text { 2. O atendimento médico } \\
\text { ao fibromiálgico entedia, } \\
\text { gera frustração, traz } \\
\text { sentimento de impotência, } \\
\text { gerando indisposição no } \\
\text { atendimento. Produz } \\
\text { cansaço, exaurindo o } \\
\text { médico pela exigência da } \\
\text { expectativa de cura. (1, 2, } 3, \\
\text { 4, 6) }\end{array}$ & $\begin{array}{l}\text { 1. O atendimento ao } \\
\text { fibromiálgico dependerá } \\
\text { dos efeitos desse paciente } \\
\text { sobre o estado de espírito } \\
\text { do médico. Esse } \\
\text { atendimento entedia, } \\
\text { causa frustração, traz } \\
\text { sentimento de impotência } \\
\text { e gera, inclusive, } \\
\text { indignação. Produz } \\
\text { cansaço, exaurindo o } \\
\text { médico pela exigência do } \\
\text { paciente, que tem a } \\
\text { expectativa de cura. }(1,2)\end{array}$ \\
\hline
\end{tabular}




\section{DISCUSSÂO}

A primeira proposição traz que o atendimento ao fibromiálgico dependerá dos efeitos desse paciente sobre o estado de espírito do médico. Esse atendimento entedia, causa frustração, traz sentimento de impotência e gera, inclusive, indignação. Produz cansaço, exaurindo o médico pela exigência do paciente, que tem a expectativa de cura.

Ao se analisar está proposição, percebe-se o despreparo do profissional médico quanto ao estado emocional e que este pode estar alterado em função do cansaço, do estresse do trabalho em relação ao meio ambiente e da carga de exigência, entre outros. E o atendimento ao paciente com fibromialgia exaure ainda mais as energias vitais do médico, pela exigência e expectativa do paciente sobre o médico. É interessante notar que este tipo de atendimento causa (fortes) emoções que mexem com a autoestima do profissional, como frustração, impotência e indignação.

Supõe-se que o profissional mais bem preparado emocionalmente já tenha vencido algumas barreiras em termos de compreensão de seus reais limites de atuação e que, portanto, sofra menos com a expectativa de cura do paciente.

Sabe-se que o paciente fibromiálgico possui alterações emocionais em função de sua personalidade e/ou da dor sentida, que pode ser até incapacitante, prejudicando em muito todas as relações e a qualidade de vida.

Neste ponto, cabe ao médico uma reflexão quanto ao que lhe incomoda no atendimento ao fibromiálgico: é não estar preparado para lidar com a angústia do paciente ou não estar preparado para lidar com a própria angústia?

A segunda proposição aborda que o paciente fibromiálgico sofre preconceito e resistência médica em virtude de múltiplas pressões exercidas sobre o profissional, tais como: idiossincrasias do paciente e a descoberta daquilo que mais o incomoda. Componentes sociais e a não adesão ao tratamento exigem um exaustivo exercício de perseverança do médico.

O preconceito significa uma ideia, uma opinião formada antecipadamente. A questão a ser entendida é: “O quê e quando se formou o conceito sobre o fibromiálgico como um paciente que exige muito do profissional médico?".

O residente apreende informações e aprende por modelos. Supõe-se que o preconceito e a resistência médica ao atendimento ao fibromiálgico sejam mais amplos, transpondo a barreira da instituição hospitalar, caminhando inclusive para o campo acadêmico, pois é nele que estudantes recebem informações quanto às técnicas de diagnóstico, tratamento e atendimento ao paciente e, também, desenvolvem o papel profissional.
Se o residente se sente desgastado devido ao preconceito em relação a este tipo de paciente, levando-o a ter resistência no atendimento, sentindo-se pressionado em virtude das idiossincrasias do paciente e da dificuldade diagnóstica da fibromialgia, talvez falte ao profissional maior preparo para atender o sofrimento humano e dar conta de suas próprias angústias e limitações de seu papel profissional.

Os componentes sociais e a não adesão ao tratamento, que exigem do médico um exaustivo exercício de perseverança, tornam-se importantes em função do despreparo em atender "os males humanos" e em ser continente, pois qualquer doença é marcada por vários fatores (físicos, emocionais, sociais, familiares, financeiros, etc.), e a fibromialgia não foge a esse contexto. Inclusive, ela é marcada por sintomas emocionais intimamente ligados às características da personalidade dos pacientes, sendo que a dor, tida como o fator mais importante, sofre influência direta do estado emocional do paciente, afetando corpo, mente e ambiente.

Cabe a este tipo de atendimento uma visão mais ampla do residente quanto aos seus próprios aspectos emocionais, além do estado emocional do paciente. Cabe à formação de médico um modelo de "cuidador", aquele que acolhe a "dor".

A terceira proposição sustenta que o médico necessita de preparo emocional para atender o fibromiálgico. São requisitos necessários: saber ouvir, ter paciência, solidariedade, compaixão e compreensão da relação paciente-doença, pois o paciente, além do adoecimento físico, tem uma carência emocional. Atender e tratar o fibromiálgico dependem mais do paciente do que da ação médica, devido a um não comprometimento grave do organismo, o que inspira maior tranquilidade no atendimento.

Percebe-se que o próprio residente aborda como um requisito necessário um preparo, um apoio emocional para atender o sofrimento humano. Não são apenas requisitos necessários, mas fazem parte do papel do médico saber ouvir, ter paciência, solidariedade, compaixão e compreensão da relação paciente-doença.

Pensar sobre isto implica dois pontos distintos, mas que convergem entre si:

a) Se há necessidade de maior preparo emocional do médico para atender o fibromiálgico, isto implica que faltou ou que não houve uma ação suficiente no campo acadêmico para este aprendizado;

b) Se há necessidade de maior preparo emocional do médico e se ele percebe isto, o que tem feito para resolver a questão?

Ponto de convergência: será que no âmbito acadêmico o estudante de Medicina foi ensinado a valorizar o aspecto emocional? Provavelmente, não foi suficientemente orientado a fazê-lo, 
porque, se tivesse sido, não hesitaria em buscar ajuda para o seu próprio desenvolvimento. O profissional da saúde faz terapia como um instrumento para aprimorar seu desenvolvimento como cuidador?

O residente percebe como necessário maior preparo emocional para atender o fibromiálgico, porém não sabe muito bem como obter esse preparo. Isto pode acontecer em decorrência da ciência, que promove a divisão entre corpo e mente, e, portanto, conteúdos emocionais se tornam de menor importância para o médico enquanto pessoa e cuidador. Verifica-se apenas uma citação de um residente que faz terapia.

Se os aspectos emocionais que envolvem o adoecer fossem vistos como importantes para o estabelecimento da relação médico-paciente e o tratamento, por que existem dificuldade e preconceito no atendimento ao fibromiálgico?

Um mecanismo encontrado pelo residente para diminuir a própria frustração gerada por este tipo de atendimento é sentir-se tranquilo pela não gravidade da doença e atribuir maior responsabilidade ao paciente na cura, pois assim se distancia do processo e se ausenta de uma compreensão maior de suas atitudes em relação ao paciente.

O afastamento por parte do médico, de seu paciente, faz com que este se sinta rejeitado. Normalmente, o fibromiálgico apresenta alterações emocionais, então o sentimento de rejeição fará com que se sinta pior e muito mais inseguro na relação médico-paciente, e, consequentemente, cobre maior apoio de seu médico.

A quarta proposição cita que o diagnóstico é marcado pela falta de comprovação laboratorial, pela subjetividade da anamnese, por múltiplos fatores que dificultam o atendimento médico e a compreensão do tratamento por parte do paciente. Todos estes fatores podem levar a uma inadequação de diagnóstico.

Percebe-se que há falta de escuta no atendimento ao fibromiálgico, pois a maior preocupação do residente é que o diagnóstico - marcado pela falta de comprovação laboratorial e pela "subjetividade da anamnese", ou seja, ouvir o que o paciente diz e aquilo que é observado - perde importância frente ao exame laboratorial, o que torna difícil orientar e tratar o paciente.

Este tipo de atendimento deveria se iniciar pela escuta, pois se sabe que o fibromiálgico é um paciente com dificuldades emocionais que permeiam o sentir a "dor" e cujo tratamento depende de múltiplos fatores.

A comunicação entre médico e paciente, quando deficitária, interfere na adesão ao tratamento. Portanto, atitudes de acolhimento, conforto, compreensão e orientação podem funcionar positivamente em relação à melhora do paciente.
A quinta proposição aborda que o próprio médico identifica como necessário o apoio da psicologia para auxiliá-lo na orientação, na explicação e na mudança de atitude do paciente em relação à doença, pois o resultado do tratamento tem eficiência na mudança de hábito e não na utilização da medicação. É um tratamento que requer uma equipe multidisciplinar devido à complexidade de fatores presentes no adoecimento. Sabe-se da necessidade de exercício físico e acompanhamento psicológico, aliados à medicação, para obtenção de resultado positivo.

Sabe-se que a satisfação, a compreensão e a adesão ao tratamento por parte do paciente estão relacionadas ao fornecimento de informações pelo médico. Por isso, é fundamental a opinião do residente quanto a ter apoio da psicologia para auxiliá-lo a atender o paciente de forma mais adequada. Isto seria ideal não somente para os casos de fibromialgia, mas para os atendimentos em geral, pois todo doente apresenta conflitos emocionais pertinentes à condição de adoecimento, além de uma estrutura de personalidade que the permite enfrentar ou não um estado de doença.

Verificou-se que uma disciplina da graduação em Medicina trata dos aspectos humanísticos da relação médico-paciente e estudante. Porém, vê-se também que as disciplinas ao longo do curso não estão suficientemente integradas devido às departamentalizações que o modelo de ensino-aprendizagem impõe.

O resultado desta formação se verifica no pedido do residente de que a área da psicologia o auxilie a orientar e a dar explicações ao paciente para que ocorra uma mudança de atitude em relação à doença. Ou seja, o modelo de médico hipocrático, conhecedor da alma humana, está sendo deixado de lado na formação do profissional.

As citações dos residentes revelam que a atenção do médico está voltada para cuidar do corpo, e quem cuida da é mente o psicólogo. Esta visão bipartida pode fazer com que o médico valorize as doenças segundo seu grau de gravidade, deixando que o paciente resolva sozinho as doenças que inspiram menos cuidado ou que envolvam mais os aspectos emocionais.

Estabelecer um relacionamento médico-paciente requer uma escuta, um olhar sobre o que sofre. É necessário compreender o comportamento humano, só assim será possível diagnosticar e tratar o paciente.

Por mais que as diretrizes curriculares apontem um ensino com dimensões éticas e humanísticas com o intuito de desenvolver no aluno atitudes e valores voltados para a cidadania, as proposições citadas demonstram que o residente se formou em Medicina despreparado para atender "as mazelas humanas". 
O tratamento da fibromialgia requer uma equipe multidisciplinar devido à complexidade dos fatores presentes no adoecimento. Sabe-se da necessidade de exercício físico e acompanhamento psicológico, aliados à medicação, para obtenção de resultado positivo. Desta forma, envolvem-se profissionais de outras áreas que em muito podem contribuir com o paciente e, principalmente, com o desenvolvimento de todos os profissionais, pois o maior aprendizado se estabelece por meio das interações.

Recai sobre a disciplina de Psicologia Médica a adequação da formação do profissional médico no estabelecimento das relações interpessoais. Talvez caiba aqui ampliar a visão não só da disciplina, mas da própria grade curricular para desenvolver trabalhos com a equipe multidisciplinar. Isto propiciaria realmente um aprendizado a partir das vivências e experiências adquiridas com o paciente, com os professores e com os outros profissionais, concebendo o homem com uma visão biopsicossocioespiritual e a profissão como uma rede com interfaces culturais.

Analisando-se cada instituição quanto à manifestação de seus residentes, nas asserções articuladas obtem-se a seguinte leitura:

a) Os médicos do hospital A falam mais em preconceitos, indisposição de atendimento devido ao paciente poliqueixoso, dificuldade em relação aos aspectos sociais, psicológicos, reumatológicos e múltiplos fatores que interferem no tratamento. Abordam a necessidade de saber ouvir e ter paciência, e solicitam mais preparo emocional do médico. Dos seis residentes, dois pedem equipe multidisciplinar. Trazem mais seus sentimentos e a percepção em relação ao doente;

b) Os médicos do hospital B falam mais de exaustão e preconceitos do atendimento pelo tipo de paciente poliqueixoso, o que faz com que o médico necessite de maior preparo. Resistência ao atendimento quando aparece um ganho secundário com a doença. Dos dois residentes, um deles vê a necessidade de uma equipe multidisciplinar. Trazem mais a indignação que o doente lhes causa com o ganho secundário;

c) Os médicos do hospital C demonstram menor preocupação com a doença por ela não ser grave e não comprometer o organismo, vendo até como satisfatória a evolução na maioria dos casos. Acreditam que existem muitos diagnósticos inadequados por falta de comprovação laboratorial e que fica tudo por conta da subjetividade da anamnese. Julgam que é necessária empatia e demonstração de confiança, mas que conversar e dar conta do emocional do paciente não fazem parte do papel profissional do médico. Acreditam que o atendimento causa indisposição por se tratar de paciente poliqueixoso e que a sensação de desgaste pode ser diminuída com a compreensão do paciente em relação à doença.
Daí, pensam que buscar qualidade de vida é mais importante que a cura, que só usar medicação não funciona, por isso a equipe multidisciplinar é importante. Dos sete residentes, quatro solicitam o acompanhamento da equipe. Veem como sendo do paciente a maior responsabilidade pelo tratamento e por isso se colocam à parte do processo.

Ao se analisarem as instituições em separado, percebe-se um padrão que marca a fala dos residentes, um pensamento que orienta a conduta, a visão que se tem do paciente. Por estarem cursando o segundo ano de residência, já adquiriram uma noção do que é esperado deles no curso. Os residentes vieram de instituições de ensino diferentes daquela em que fazem a residência. Portanto, o fator graduação como direcionador da conduta é apenas parcial, mas não menos importante.

Pode-se pensar que a instituição na graduação tem um papel na formação do estudante enquanto modelo e direcionador. É nesta fase que se dá a relação ensino-aprendizagem, portanto, é aqui que se apreende o sentido de ser médico. Porém, na residência, os estudantes, agora já profissionais e vindos de diferentes instituições de ensino, se percebem inseridos no contexto da especialidade escolhida. Então, a busca é formar uma opinião, obter uma visão, adquirir competência, habilidade e atitudes que os reportam ao mercado de trabalho como bons profissionais.

Alguns pontos devem ser elucidados, entre eles: (a) a metodologia qualitativa é pouco usada na área da saúde, o que leva o profissional a ter dificuldades na obtenção de referências bibliográficas e até de exposição e aceitação de sua pesquisa; (b) a resposta do doente à doença e ao tratamento; a própria doença; a dificuldade de diagnóstico e de tratamento; e a disponibilidade de recursos humanos e materiais não foram citados pelos residentes como agentes estressores. Isto não significa que não se tornarão estressores, mas o que fica caracterizado é que atender o fibromiálgico é mais frustrante do que estressante, pois atinge diretamente a conduta médica. Por isso, um dos mecanismos para evitar a angústia é o distanciamento na relação médico-paciente, a negação da importância do indivíduo e da doença, e a tentativa de reduzir o peso da responsabilidade e o comprometimento com o doente e a doença, transferindo a "cura" para o paciente.

\section{CONCLUSÕES}

Demarca-se a compreensão do atendimento ao fibromiálgico como um ato difícil e elaborado, em função dos múltiplos fatores existentes, que dificultam o diagnóstico e o tratamento e que requerem habilidades de escuta mais desenvolvidas do que se tem no momento, gerando frustração ao residente. 
O residente explicitou a compreensão ao atendimento ao paciente fibromiálgico marcada pelas cinco proposições finais deste estudo e de onde se podem tirar as conclusões seguintes.

O exercício profissional do médico se tornará mais eficaz quando articular os conhecimentos teóricos e técnicos aos aspectos afetivos, sociais, culturais e éticos da relação médico-paciente, desenvolvendo a capacidade de escuta. Para isto, é preciso melhor preparação quanto aos conteúdos humanísticos relacionados ao adoecer durante a graduação e a residência.

A mudança do perfil do médico está intimamente ligada à mudança dos rumos da escola médica. A mudança do paradigma reducionista é necessária para o alcance da excelência profissional no estabelecimento das relações humanas e do compromisso social, sem deixar a ciência de lado, mas utilizando recursos internos, como a capacidade de observação e a intuição, entre outros, para a realização dos diagnósticos.

O médico precisa trabalhar os aspectos emocionais próprios, durante e após sua formação profissional, pois seu estado emocional e de humor podem interferir na comunicação com o paciente e causar baixa adesão ao tratamento. Esta pesquisa propicia uma reorientação aos profissionais da área da saúde que realizam atendimentos a dores crônicas quanto a seus posicionamentos frente ao acolhimento da "dor". É preciso maior preparo do estado emocional do médico, pois cuidar de saúde é, em primeiro lugar, ter saúde (biopsicossocial).

A equipe multidisciplinar é um caminho para o desenvolvimento profissional e para o melhor atendimento ao paciente. Desta forma, os profissionais aprenderão pelo processo de interação e de conscientização de seus limites.

\section{REFERÊNCIAS}

1. Falcão DM. Terapia cognitivo-comportamental para o tratamento de paciente fibromiálgico: estudo controlado randomizado. São Paulo; 2004. Doutorado [Tese]-UNIFESP.

2. Yoshikawa GT. Comparação da qualidade de vida entre homens com fibromialgia e depressão. São Paulo; 2005. Mestrado [Dissertação] - UNIFESP.

3. Bernardo CLE. Dor: o ensino do tema em curso de graduação em enfermagem da região sudeste do Brasil. São Paulo; 1998. Mestrado [Dissertação] - UNIFESP.

4. Feldman, C. Atendendo o paciente. $2^{\underline{a}}$ ed. Belo Horizonte: Crescer; 2002.

5. Barros ALBL, Humerez, DC, Fakih FT, Michel, JLM. Situações geradoras de ansiedade e estratégias para seu controle entre enfermeiras: estudo preliminar. Rev Lat Am Enfermagem. 2003;11(5): 585-92. DOI: 10.1590/S0104-11692003000500004
6. Gadamer HG. Verdade e método II. 6 $6^{\underline{a}}$ ed, São Paulo: Vozes; 2004b.

7. Ismael JC. O médico e o paciente. São Paulo: Queiroz, 2002.

8. Nogueira-Martins MCF. Humanização das relações assistenciais: a formação do profissional de saúde. $2^{\underline{a}}$ ed. São Paulo: Casa do Psicólogo; 2002.

9. Batista NA. Conhecimento, experiência e formação: do médico, do professor de medicina. Estudo sobre a disciplina formação didático-pedagógica em saúde nos cursos de pós-graduação. São Paulo;1997. Livre-Docência [Tese] UNIFESP.

10. Milan LR. Vocação médica. São Paulo: Casa do Psicólogo; 2005.

11. Feuerwerker L. Além do discurso de mudança na educação médica: processo e resultados. São Paulo: Hucitec; 2002.

12. Lampert JB. Tendências e mudanças na formação médica no Brasil: tipologia das escolas. São Paulo: Hucitec; 2002.

13. Fagnani-Neto R. Cuidando de residentes de medicina e outros trainees na área da saúde: a experiência do Núcleo de Assistência a Pesquisa em Residência Médica (NAPREME). São Paulo; 2003. Mestrado [Dissertação] - UNIFESP.

14. Macedo PCM. Avaliação de qualidade de vida em residente-médico da Escola Paulista de Medicina. São Paulo; 2004. Mestrado [Dissertação] - UNIFESP.

15. Minayo MCS. O desafio do conhecimento: pesquisa qualitativa em saúde. 8a ed. São Paulo: Hucitec; 2004.

16. Rossi PS. O ensino da comunicação na graduação: uma abordagem. São Paulo; 2004 [Dissertação] - UNIFESP.

17. Laurenti RB. Psicopedagogia: um modelo fenomenológico. 1ํㅡㄹ ed. São Paulo: Vetor 2004.

18. Feijoo, AMLC. A escuta e a fala em psicoterapia. São Paulo: Vetor; 2000.

19. Gadamer HG. Verdade e método I. $6^{a}$ ed. São Paulo: Vozes; 2004a.

20. Turato ER. Tratado da metodologia qualitativa da pesquisa clínico-qualitativa. Petrópolis: Vozes; 2003.

\section{CONTRIBUIÇÃO DOS AUTORES}

Ana Maria Canzonieri Maeda - autora do trabalho para a apresentação como dissertação de mestrado em Ciências da Saúde, a disciplina de reumatologia, para a UNIFESP.

Prof Dr Daniel Feldman - professor orientador do trabalho na área médica em relação aos residentes e a fibromialgia.

Profa Dra Maria Anita V. Martins - professora co-orientadora do trabalho na área da fenomenologia. 


\section{CONFLITO DE INTERESSES}

Declarou não haver

\section{ENDEREÇO PARA CORRESPONDÊNCIA}

Ana Maria C. Maeda
Rua Dr. Cesar, 530 - sala 1605

Santana - São Paulo

CEP.: 02013-002 SP

E-mail: anna05@accompe.com.br 